\title{
Effects of antimony addition on growth of InGaN nano-structures by mixed-source HVPE
}

Jin Eun Ok, Dong Wan Jo, Hun Soo Jeon, Ah Reum Lee, Gang Suok Lee, Young Ji Cho, Kyung Hwa Kim, Ji Ho Chang, Hyung Soo Ahn and Min Yang ${ }^{\dagger}$

Department of Applied Science, Korea Maritime University, Busan 606-791, Korea

(Received May 28, 2010)

(Revised June 9, 2010)

(Accepted June 11, 2010)

\begin{abstract}
We report on the growth and characteristics of the structural and optical properties of InGaN nano-structures doped with antimony ( $\mathrm{Sb}$ ) as a catalyst. The use of catalyst has been explored to modify the growth and defect generation during strained layer heteroepitaxial growth. We performed the growth of the InGaN nano-structures on c-sapphire substrates using mixed-source hydride vapor phase epitaxy (HVPE). The characteristic of samples was measured by scanning electron microscope (SEM) and photoluminescence (PL). The aligning direction of c-axis of the InGaN nanostructures was changed from vertical to parallel or inclined to the surface of substrates when the $\mathrm{Sb}$ was added as a catalyst. The indium composition was estimated about $3.2 \%$ in both cases of with or without the addition of $\mathrm{Sb}$ in the InxGa1-xN structures. From the results of InGaN nano-structures formed with the addition of $\mathrm{Sb}$, we can expect the performance of optical devices would be more improved by reduced piezo-electric field if we use the InGaN nanostructures of which c-axes are aligned parallel to the substrates as an active layer.
\end{abstract}

Key words InGaN, HVPE, Mixed-source, Nano-structures, Antimony, Catalyst

\section{혼합소스 HVPE 방법에 의한 InGaN 나노구조의 성장에 있어서 Sb 첨가의 영향}

옥진은, 조동완, 전헌수, 이아름, 이강석, 조영지, 김경화, 장지호, 안형수, 양민

한국해양대학교 응용과학과, 부산, 606-791

(2010년 5월 28일 접수)

(2010년 6월 9일 심사완료)

(2010년 6월 11일 게재확정)

요 약 본 논문에서는 $\mathrm{Sb}$ 를 촉매제로 이용하는 경우의 $\mathrm{InGaN}$ 나노구조의 성장과 구조적 특징 및 광학적 특성에 대해 서 연구하였다. 결정성장에 있어서 촉매제의 사용은 성장 모드의 변화와 결정 결함의 감소 등을 위한 목적으로 많이 사용 되어 왔다. 본 연구에서는 혼합소스 HVPE(hydride vapor phase epitaxy) 사용하여 (0001) 사파이어 기판 위에 $\mathrm{InGaN}$ 나노구 조를 성장하였고, 구조적 및 광학적 특성은 scanning electron microscope(SEM)과 photoluminescence(PL)를 통해 평가하였다. $\mathrm{Sb}$ 이 첨가되지 않은 경우에는 $\mathrm{InGaN}$ 나노구조가 $\mathrm{c}$-축 방향으로 정렬되는 경향을 보이지만 $\mathrm{Sb}$ 이 첨가된 경우에는 $\mathrm{InGaN}$ 나노구조의 c-축 방향이 기판에 대해 평행하거나 경사진 방향으로 정렬되고 있는 것을 관찰할 수 있었다. In의 조성은 $\mathrm{Sb}$ 의 첨가 여부에 관계없이 약 $3.2 \%$ 정도로 계산되었다. 이러한 결과들로부터 측면 배향된 나노입자를 활성층으로 하는 광 소자에 적용할 경우 압전 전계를 완화할 수 있기 때문에 광소자의 발광 성능을 향상시킬 수 있을 것으로 기대된다.

\section{1. 서 론}

화합물 반도체는 광소자의 재료로서 오래 전부터 주목 받아 왔으며 특히, 큰 밴드갭 에너지를 가지는 III-V 족

\footnotetext{
${ }^{\top}$ Corresponding author

Tel: +82-51-510-4782

Fax: +82-51-404-3986

E-mail: myang@hhu.ac.kr
}

반도체 물질의 특성에 대해서 최근 많은 연구들이 진행 되어 왔다[1-4]. 여러 종류의 III-V 족 화합물반도체 중 에서 대표적인 질화물 반도체라고 할 수 있는 $\mathrm{GaN}$ 과 $\mathrm{In}_{\mathrm{x}} \mathrm{Ga}_{1-\mathrm{x}} \mathrm{N}$ 는 자외선 영역, 가시광 영역 그리고 적외선 영역의 매우 넓은 파장영역에서 이용할 수 있는 특징이 있어서 다양한 종류의 발광소자 제작에 이용되고 있다. 특히, 나노 크기의 $\mathrm{InGaN}$ 구조는 상태 밀도의 감소, 전위 밀도와 응력의 완화, 캐리어 가둠 효과의 증가로 기존의 
2차원 박막구조에서는 기대할 수 없는 장점들을 가지고 있기 때문에 우수한 특성을 가지는 활성층으로의 응용을 목적으로 이에 대한 활발한 연구가 진행되고 있다 $[5,6]$.

그러나 현재 보편적으로 사용되고 있는 c-plane 방향 으로의 질화물 반도체 결정성장은 분극의 영향으로 이종 접합 구조의 계면에서 강력한 전기장을 발생시켜 양자우 물구조의 광소자에 있어서 전자와 정공이 분리되는 원인 이 된다. 이러한 전자와 정공의 공간적 분리는 $\mathrm{LED}$ 에 있어서 red shift의 원인이 되며 photon 생성에 있어서도 내부 양자효율이 크게 낮아져 외부 광출력 향상에 한계 가 있기 때문에 최근에는 이러한 문제를 극복하기 위해 서 무극성 및 반극성 결정성장에 대한 연구들이 많이 진 행되고 있다[7-10]. 결정성장 방향을 조절하는 또 다른 접근 방법은 결정 성장을 실시하는 동안 촉매역할을 하 는 원료를 첨가하는 방법이 있는데 유기금속기상성장법 (MOVPE: metal organic vapor phase epitaxy)과 분자 선에피탁시(MBE: molecular beam epitaxy) 결정성장 방법에서 $\mathrm{GaN}$ 결정을 성장하는 동안 $\mathrm{Sb}$ 를 첨가함으로 써 성장 모드의 변화와 결정 결함의 감소 등 다양한 특 성의 변화들이 있음을 보고한 사례들이 있다[11, 12].

본 논문에서는 기존의 HVPE 방법 대신에 혼합 소스 HVPE 방법을 이용하여 (0001) 사파이어 기판 위에 InGaN 나노구조 형성시 $\mathrm{Sb}$ 의 첨가가 결정성장의 형태에 어떠 한 영향을 주게 되는지를 확인하였다. 기존의 HVPE 방 법에서는 $\mathrm{InGaN}$ 결정성장을 위해서 $\mathrm{III}$ 족 원료 $(\mathrm{Ga}, \mathrm{In})$ 및 $\mathrm{Sb}$ 을 각각 공급하는 구조로 되어 있어서 반응관 부 분의 설계가 쉽지 않고 가스 유속 제어 장치가 많이 필 요하다는 단점을 가지는 반면에 혼합소스 HVPE 방법에 서는 $\mathrm{Ga}$ 금속에 특정 비율의 $\mathrm{In}$ 금속 및 $\mathrm{Sb}$ 금속을 직 접 녹여서 사용하기 때문에 비교적 장치가 간단하다는 특징을 가지고 있다. 혼합 소스 HVPE 방법은 $\mathrm{InGaN}$ 성장뿐만 아니라 $\mathrm{Ga}$ 금속에 용해도를 가지는 대부분의 금속 원료를 녹여서 사용할 수 있으므로 간단한 방법에 의해 새로운 물질의 합성과 성장기구 및 특성을 이해하 는 데에 크게 활용될 수 있을 것으로 기대가 된다.

(0001) 사파이어 기판 위에 성장된 $\mathrm{InGaN}$ 나노구조의 $\mathrm{Sb}$ 첨가에 의한 결정 형상의 변화는 FE-SEM(field emission scanning electron microscope)을 이용하여 관찰하 였고 상온 $\mathrm{PL}$ (photoluminescence)를 통해 광학적 특성 들을 평가하였다.

\section{2. 실험방법}

본 연구에서는 수평형 혼합소스 HVPE 방법을 이용하 여 (0001) 사파이어 기판 위에 $\mathrm{InGaN}$ 나노구조를 성장 하였다. InGaN 나노구조를 성장하기 위해 III족 원료로
는 금속 $\mathrm{Ga}$ 과 $\mathrm{In}$ 을, $\mathrm{V}$ 족 원료로는 암모니아 가스를 사 용하였다. 혼합 형태의 금속 원료는 Ga $1 \mathrm{~g}$, In $10 \mathrm{~g}$ 을 함께 용융 시켜 사용하였으며 원료영역의 온도는 $700^{\circ} \mathrm{C}$ 로 유지시켰다. 혼합소스의 표면 위로 $\mathrm{HCl}$ 을 흘려주어 In 및 $\mathrm{Ga}$ 의 염화물을 형성하여 성장영역에서 암모니아 가스와의 화학적 반응을 하도록 하여 $\mathrm{InGaN}$ 나노구조를 형성하였다. 이 때 $\mathrm{HCl}$ 과 암모니아의 가스유량은 각각 $20 \mathrm{sccm}, 500 \mathrm{sccm}$ 으로 하였으며 $550^{\circ} \mathrm{C}$ 에서 20 분 동안 성장하였다. 한편, $\mathrm{Sb}$ 의 첨가에 따른 특성 변화를 알아 보기 위해 금속 $\mathrm{Ga}(1 \mathrm{~g})$ 과 $\mathrm{In}(10 \mathrm{~g})$ 을 혼합한 원료에 추 가로 $\mathrm{Sb}(1 \mathrm{~g})$ 를 첨가하였으며 다른 성장 조건들은 $\mathrm{Sb}$ 을 첨가하지 않은 경우와 동일하게 실시하였다.

\section{3. 결과 및 고찰}

본 논문에서는 $\mathrm{Sb}$ 을 첨가하지 않은 시료는 $\mathrm{A}, \mathrm{Sb}$ 를 첨가한 시료는 $\mathrm{B}, \mathrm{C}$ 라고 표기하였는데 $\mathrm{B}$ 는 $\mathrm{Sb}$ 을 첨가 한 혼합 원료를 사용하여 처음 20 분 동안 성장한 시료 이며, $\mathrm{C}$ 는 원료의 추가 보충없이 80 분 동안 원료를 $\mathrm{HCl}$ 반응에 의해 일정량이 감소되도록 한 후에 $\mathrm{B}$ 의 시 료와 동일한 조건으로 성장한 시료이다.

Fig. 1은 $\mathrm{Sb}$ 첨가 여부에 따른 (0001) 사파이어 기판 위에 성장된 $\mathrm{InGaN}$ 나노구조의 표면 $\mathrm{SEM}$ 측정 결과이 다. 시료 $\mathrm{A}$ (Fig. 1(a))의 표면 사진에서는 나노 구조가 $\mathrm{c}$-축 방향으로 정렬되는 경향을 보이지만 시료 $\mathrm{B}(\mathrm{Fig}$. 1(b))의 경우는 c-축 방향이 기판에 평행한 형태로 나노 구조가 형성되고 있는 것으로 관찰되었다. $\mathrm{Sb}$ 첨가 여부 에 따라서 $\mathrm{InGaN}$ 나노구조의 결정성장 방항이 큰 차이 를 보이는 것은 결정 방향에 따른 표면 포텐셜 에너지가 $\mathrm{Sb}$ 의 촉매 작용에 의해 변하기 때문인 것으로 추측된다 [13]. 시료 $\mathrm{A}$ 와 시료 $\mathrm{B}$ 의 $\mathrm{InGaN}$ 나노구조의 정렬 방향 에 차이를 보이는 결과로부터 $\mathrm{Sb}$ 이 측면 방향 (\{10-10\} 또는 $\{11-20\})$ 의 표면에너지를 더 감소시키는 역할을 하 는 것으로 판단된다. 시료 $\mathrm{C}(\mathrm{Fig} .1$ (c) $)$ 의 경우는 금속 원료의 사용시간이 길어짐에 따라 혼합 원료내의 각 금 속성분들의 비율이 시료 $\mathrm{B}$ 의 경우에 비해 차이가 있기 때문에 성장 영역에서 $\mathrm{Sb}$ 의 촉매 역할에 변화가 생겨서 수직으로 정렬된 나노구조와 약 45도 각도로 경사진 나 노구조들이 동시에 존재하는 형태를 보이고 있다. 그러 나 뒤에서 언급하게 되듯이 시료 $\mathrm{A}, \mathrm{B}$ 그리고 $\mathrm{C}$ 의 $\mathrm{In}$ 조성비는 동일한 결과를 보였다. 따라서 $\mathrm{Sb}$ 은 $\mathrm{InGaN}$ 나 노구조에 있어서 In의 조성비 변화에는 영향을 주지 않 고 단지 결정 성장 방향의 변화에만 영향을 주는 촉매 역할을 하는 것으로 추측된다. 혼합 금속 원료의 사용시 간에 따른 각 금속 성분들의 변화 비율과 그 때의 $\mathrm{Sb}$ 의 촉매 역할의 변화에 대한 정확한 현상 규명은 추후 실험 

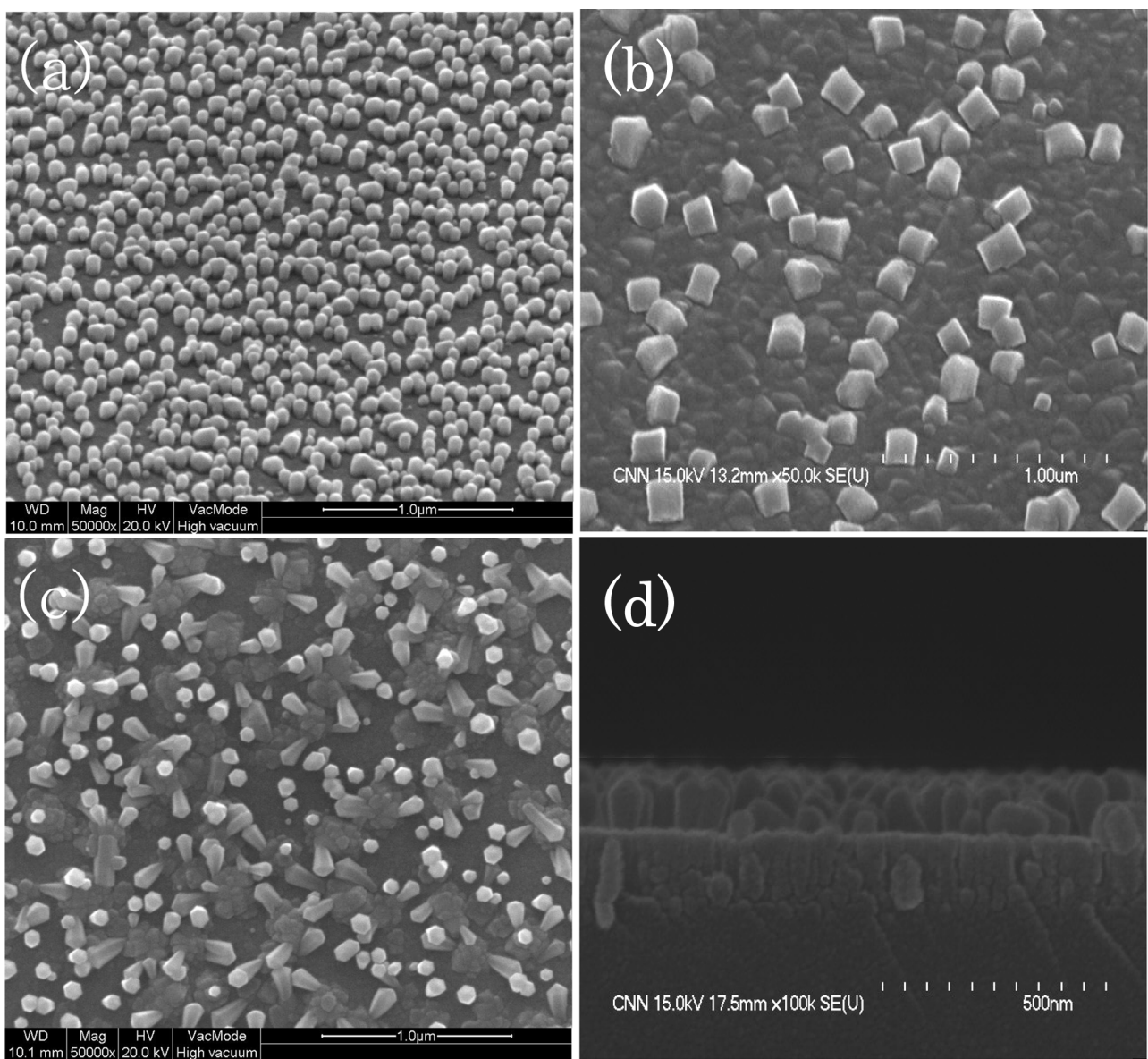

Fig. 1. The SEM images of InGaN nano-structures grown on c-sapphire substrate (a) without $\mathrm{Sb}$, (b) and (c) with $\mathrm{Sb}$ and (d) crosssectional SEM image of InGaN structures.

할 예정이다. Fig. 1(d)는 (0001) 사파이어 기판 위에 성 장된 $\mathrm{InGaN}$ 나노구조(시료 $\mathrm{A}$ )의 단면 $\mathrm{SEM}$ 사진을 보 여준다. InGaN 나노구조의 성장 모드는 Layer-by-layer (2D) 성장에서 $3 \mathrm{D}$ islands 성장하는 전형적인 $\mathrm{S}-\mathrm{K}$ 성장 모드를 보이고 있는데 본 성장 조건에서는 약 $160 \mathrm{~nm}$ 의 두께를 경계로 하여 2차원 성장에서 3 차원 성장으로 변 화되는 결과를 보이고 있다.

Fig. 2에는 $\mathrm{Sb}$ 첨가에 따라 $\mathrm{InGaN}$ 나노구조의 평균적 인 밀도와 길이의 결과를 보였다. 시료 $\mathrm{A}$ 의 나노구조의 밀도는 평균적으로 $7.6 \times 10^{9} \mathrm{~cm}^{-2}$ 이며 시료 $\mathrm{B}$ 와 $\mathrm{C}$ 의 경 우는 각각 $1.8 \times 10^{9} \mathrm{~cm}^{-2}, 2.7 \times 10^{9} \mathrm{~cm}^{-2}$ 임을 확인할 수 있었다. 또한 평균 길이는 시료 $\mathrm{A}$ 의 경우는 약 $82 \mathrm{~nm}$ 이 며 시료 $\mathrm{B}$ 와 $\mathrm{C}$ 의 경우는 각각 $153 \mathrm{~nm}, 165 \mathrm{~nm}$ 로 확인 되었다. 따라서 $\mathrm{Sb}$ 의 첨가에 의해 밀도는 감소하고 나노 구조의 길이는 길어지는 경향을 보이는 것을 알 수 있는 데 이것은 $\mathrm{Sb}$ 을 첨가함으로써 기판에서 원자의 평균 확 산거리가 길어지기 때문이라고 판단된다.

Fig. 3은 $\mathrm{Sb}$ 첨가 여부에 따른 $\mathrm{InGaN}$ 나노구조의 상 온 PL 스펙트럼이다. 시료 $\mathrm{A}, \mathrm{B}, \mathrm{C}$ 모두 동일한 위치에 서 발광성 천이가 확인되었으며, 파장의 위치는 380

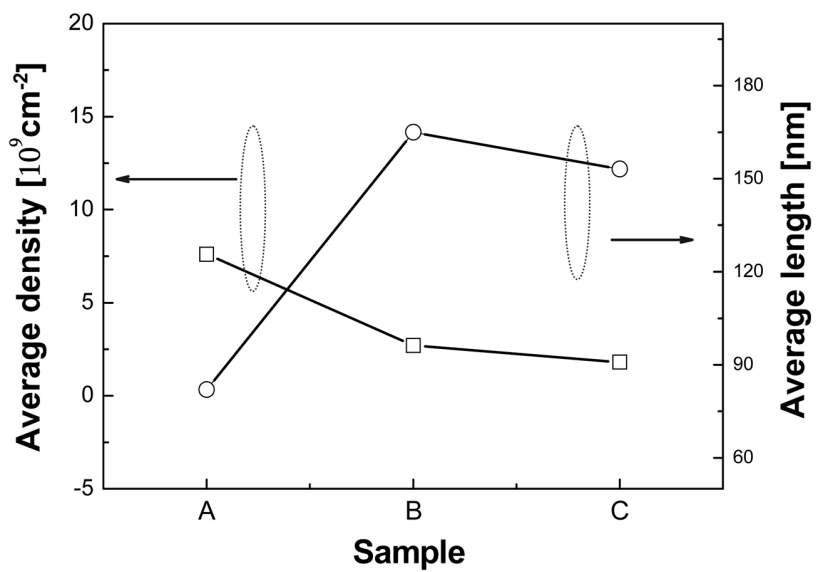

Fig. 2. Average density and length of the InGaN nano-structures grown on c-sapphire substrate.

$\mathrm{nm}, 403 \mathrm{~nm}, 428 \mathrm{~nm}$ 였다. In 조성비는 $380 \mathrm{~nm}$ 위치를 밴드단 천이로 가정하여 약 $3.2 \%$ 로 계산되었는데 이때 bowing parameter는 $\mathrm{b}=1.4 \mathrm{eV}$ 를 사용하였다[14]. 한편, $403 \mathrm{~nm}, 428 \mathrm{~nm}$ 에서의 발광성 천이는 donor-to-acceptor pair(DAP) 또는 산소나 기타 다른 불순물에 의한 것으로 


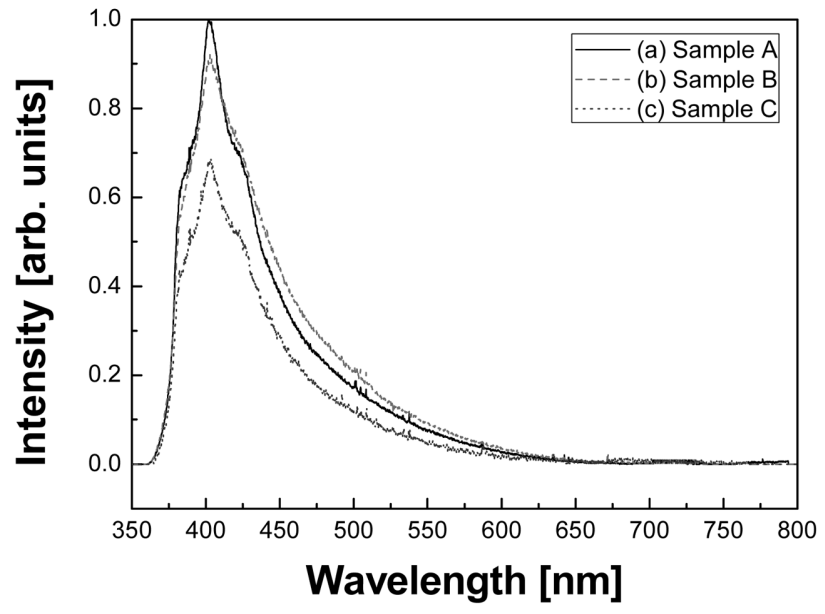

Fig. 3. The PL spectra of the InGaN nano-structures grown on c-sapphire substrates at $550^{\circ} \mathrm{C}$. (a) sample A ( without $\mathrm{Sb}$ ), (b)

Sample B (with Sb) and (c) Sample C (with $\mathrm{Sb}$ ).

생각된다. $\mathrm{Sb}$ 의 첨가 여부에 관계없이 발광성 천이 피크 등의 위치가 동일한 결과로부터 $\mathrm{Sb}$ 는 발광성 준위의 변 화에는 관여하지 않고, 촉매제로서만 작용하여 $\mathrm{InGaN}$ 나 노구조의 결정방향에 영향을 주고 있는 것으로 판단된다.

\section{4. 결 론}

혼합소스 HVPE 방법을 이용하여 $\mathrm{InGaN}$ 나노구조를 성장하였으며, HVPE 성장법에서는 처음으로 $\mathrm{Sb}$ 의 촉매 기능을 확인하였다. 표면 형상의 변화를 확인하기 위한 $\mathrm{SEM}$ 관찰 결과, $\mathrm{Sb}$ 를 첨가함으로써 $\mathrm{InGaN}$ 나노구조의 결정방향이 변하는 것을 알 수 있었다. 이것은 특정 결 정 면들에서 $\mathrm{Sb}$ 의 촉매 작용에 의해 표면 포텐셜 에너 지가 변화하기 때문이라고 생각한다. PL 측정 결과, In 의 조성은 약 $3.2 \%$ 정도로 계산되었고, $\mathrm{Sb}$ 의 첨가 여 부에 상관없이 발광성 천이 파장들의 위치가 동일한 것 을 확인하였다. 이들 결과로부터 MOCVD, MBE 방법 의 결과들과 유사하게 HVPE 방법에서도 $\mathrm{Sb}$ 은 발광성 준위의 변화에는 관여하지 않고, 촉매제로서 나노구조들 의 결정성장방향에만 영향을 준다고 판단된다. $\mathrm{HVPE}$ 방법에서 $\mathrm{Sb}$ 을 촉매제로 이용하여 나노구조의 결정방향 을 적절히 조절한다면 압전 분극 현상을 완화시킨 양자 점 구조의 활성층을 가지는 광소자를 비롯하여 그 밖에 새로운 기능 또는 향상된 기능의 광소자 또는 전자소자 등에 응용될 수 있을 것으로 기대된다.

\section{감사의 글}

이 논문은 2009년 정부(교육과학기술부)의 재원으로 한
국연구재단의 지원을 받아 수행된 연구임(2009-0088416).

\section{참 고 문 헌}

[1] S. Nakamura, S. Pearton and G. Fasol, "The Blue Laser Diode: the Complete Story" (Springer, Berlin, 2000) 237.

[2 ] K.P. O’Donnell, R.W. Martin and P.G. Middleton, Phys. Rev. Lett. 82 (1999) 237.

[3] J.I. Pankove and T.D. Moustakes, Gallium Nitride II:semiconductor and semimetals (Academic Press, New York, 1999) 57.

[ 4 ] Y. Xia, P. Yang, Y. Sun, Y. Wu, B. Mayers, B. Gates, Y. Yin, F. Kim and H. Yan, "One-dimensional nanostructures: Synthesis, characterization, and applications", Adv. Mater. 15 (2003) 353.

[ 5 ] K. Kornitzer, T. Ebner, K. Thonke, R. Sauer, C. Kirchner, V. Schwegler, M. Kamp, M. Leszczynski, I. Grzegory and S. Porowski, "Photoluminescence and reflectance spectroscopy of excitonic transitions in high-quality homoepitaxial GaN films", Phys. Rev. B 60 (1999) 1471.

[6] W.W. Chow and H.C. Schneider, "Theory of laser gain in InGaN quantum dots”, Appl. Phys. Lett. 81 (2002) 2566.

[ 7 ] R. Langer, J. Simon, W. Ortiz, N.T. Pelekanos, A. Barski, R. Andre and M. Godlewski, "Giant electric fields in unstrained GaN single quantum wells", Appl. Phys. Lett. 74 (1999) 3827.

[ 8 ] M.D. Craven, P. Waltereit, J.S. Speck and S.P. Den-baars, "Well-width dependence of photoluminescence emission from a-plane GaN/AlGaN multipled quantum wells", Appl. Phys. Lett. 84 (2004) 496.

[9] L. Zhou, R. Chandrasekaran, T.D. Moustakas and D.J. Smith, "Structural characterization of non-polar (11-20) and semi-polar (112-6) GaN films grown on r-plane sapphire", J. Cryst. Growth 310 (2008) 2981.

[10] Z.H. Wu, A.M. Fischer, F.A. Ponce, B. Bastek, J. Christen, T. Wernicke, M. Weyers and M. Kneissl "Structural and optical properties of nonpolar GaN thin films", Appl. Phys. Lett. 92 (2008) 171904.

[11] L. Zhang, H.F. Tang, J. Schieke, M. Mavrikakis and T.F. Kuech, "The addition of $\mathrm{Sb}$ as a surfactant to GaN growth by metal organic vapor phase epitaxy", J. Appl. Phys. 92 (2002) 2304.

[12] C.W. Pei, B. Turk, J.B. Heroux and W.I. Wang, "GaN grown by molecular beam epitaxy with antimony as surfactant", J. Vac. Sci. Technol. B 19 (2001) 1426.

[13] E. Kaxiras, "Atomic structure of catalyst monolayers and its role in epitaxial growth Mater", Sci. Eng. B 30 (1995) 175.

[14] W. Walukiewicz, S.X. Li, J. Wu, K.M. Yu, J.W. Ager III, E.E. Haller, Hai Lu and William J. Schaff, "Optical properties and electronic structure of $\mathrm{InN}$ and In-rich group III-nitride alloys", J. Cryst. Growth 269 (2004) 119. 